\title{
IMPROVING UNIVERSITY STUDENTS' PERCEPTIONS OF PEER ASSESSMENT
}

\author{
Elizabeth Ruiz Esparza Barajas \\ Foreign Languages Department, Universidad de Sonora (Mexico)
}

\begin{abstract}
Peer assessment is crucial in modern education which emphasizes students' active participation at every aspect of their learning. However, studies have evidenced problems in the implementation of this type of assessment and resistance towards these methods caused by students' negative perceptions. This paper describes an action research study that set out to find out and improve the perceptions about peer assessment in a group of 30 university students from the third semester of a Bachelor of Arts in English Language Teaching program in Northwest Mexico. The instruments used for data collection were observations and written interviews. Activities and strategies were designed and implemented following the stages of action research. Data was analyzed and the results suggested that the students' perceptions about peer evaluation improved in relation to the credibility and value of peer assessment.
\end{abstract}

Keywords: Peer assessment, perceptions, training university students, action research.

\section{Introduction}

Modern approaches to education and their methodologies emphasize the need for students to be active learners and responsible of their own learning. They need to be able to search for information, share knowledge with their peers, discuss and debate the different information and points of view. Then, they should continue to analyze and evaluate what was debated to come up with new understandings. In addition, the $21^{\text {st }}$ century competencies, which are clustered in three basic domains and are the cognitive, intrapersonal and interpersonal competencies, expect students to become citizens that can transform society, address inequalities, help social justice and protect the environment (UNESCO, 2013). Therefore, high quality university education should address these three domains and develop a diversity of skills to achieve these purposes in their students. Pellegrino (2017) explains that the cognitive domain clusters the knowledge, cognitive processes and creativity competencies while the intrapersonal domain is the one that develops the conscientiousness, intellectual openness, work ethic and self-regulation competencies. He also adds that the interpersonal domain includes teamwork, collaboration and leadership.

In this scenario where decision-making, collaborative work, information sharing and innovations are key factors to function in a globalized world (Binkley, Erstad, Herman, Raizen, Ripley, Miller-Ricci, \& Rumble, 2012), modern methodologies which make use of current methods of assessment are crucial to optimize learning and reach the $21^{\text {st }}$ century agenda goals. Studies have proved the need for engaging students in peer and self-assessment. Logan (2009) claims that these methods enhance the development of self-confidence, reflection and critical thinking skills while De Grez, Valcke and Roozen (2012) observed important learning gains in students after being involved in this type of assessment. And Ndoye (2017) found out that it created a more open and supportive learning environment. Therefore, peer assessment helps develop the three broad competencies: the cognitive, intrapersonal and interpersonal domains.

However, literature shows that many students have negative perceptions about peer assessment methods. Liu and Carless' (2006) found out in their study that not only students but also teachers were resistant to the use of peer assessment. They claim that the reasons for the students' resistance are their perceptions of lack of reliability and knowledge from peers as well as the power relations among peers. In another study, Carvalho (2013) reports on students' perceptions of unfairness and conflicts of friendships in peer evaluation. As peer assessment needs to be "...brought into the heart of teaching and learning processes and decision-making" as James and Pedder (2006, p. 28) suggest, steps need to be taken for training students and teachers in these methods of assessment. Therefore, this study set out to investigate the perceptions about peer assessment of a group of students that are studying to be teachers at earlier stages in the Bachelor of Arts in English Language Teaching (BA in ELT) program. 


\section{Design and role of the researcher}

The design of this study followed the qualitative approach to research and used the action research methodology. Sagor's (2000) defined action research as "a disciplined process of inquiry conducted by and for those taking the action...[in order to] assist the "actor" in improving and/or refining his or her actions" (p. 3). In this sense, the role of the researcher was participatory since the researcher implemented the steps, activities and strategies in her own classroom. The spiral steps that were followed were first the diagnosis stage in which the focus was established and literature was read. In the second step of plannification, the strategies to make students understand the concept of peer evaluation in practice and the activities for the strategies to happen were planned. In the third stage of execution, the activities and strategies were implemented and observed, notes were taken. In the fourth stage of reflection and evaluation, data was analyzed, reflected upon and the strategies and activities were evaluated for implementing another cycle.

\section{Objectives}

As the studies in the literature section of this paper suggested mixed perceptions about peer assessment, the objective of this study was to find out whether the students from the third semester of the BA in ELT program shared positive and negative perceptions about this type of assessment. Then the second objective was to see whether negative perceptions surfaced and if these could be improved. Therefore, the research questions were:

- What are the perceptions of the students from the third semester of the BA in ELT program?

- To what extent can the negative perceptions of the third semester of the BA in ELT program be improved, if any?

\section{Participants}

The participants in this study were 30 students from the third semester of the BA in ELT program in a northwest public state university in Mexico. Their ages ranged from 19 to 26 years old and the group consisted of 13 males and 17 females. The course was Introduction to teaching practice, which is a combination of theory and practice. In this introductory course, the students learn about classroom management techniques and strategies in a collaborative and simulated environment. Examples of the course content are the use of the voice, gestures, eye contact, setting groups, giving instructions, lead-ins, eliciting from students, elements in a lesson plan, etc. At the end of the course, the students present in groups a short lesson plan in which they have to include the techniques and strategies practiced in class in a microteaching session.

\section{Discussion of results}

For the diagnosis stage, the students were given a written interview with questions about their experience with peer assessment, types of peer assessment they have experienced, their opinions about this type of assessment and reasons for these opinions. The results of their experience were that 68 percent said that they had experienced peer assessment a few times during their junior and high school education and 5 percent of students said that their experience had started at elementary school. The percentage of students that had not experienced peer assessment until entering the BA in ELT program was 27. However, when analyzing the results from the type of peer assessment they had carried out, there was a diversity of situations in which most of them said that they had exchanged and graded exams (multiple choice, fill in the blanks, true or false, matching, short answer, etc.) while the teacher was dictating the correct answers. A few others said they had peer evaluated written papers in this program such as essays, proofreading them and correcting grammar, spelling and punctuation marks. Other few commented that they had given feedback after oral presentations and assessed peers, mostly in this program. Therefore, this analysis suggested that most of the students' experience before this program was summative, mechanic and guided by the teacher.

In relation to the students' opinions and their reasons, 48 percent said that they did not perceive any real value of this type of assessment. Three students shared the same perception that "the teacher was lazy" because "he wanted help" and "teachers do not want to do their job". 39 percent said that they did not mind correcting exams but they did not mention having benefitted from the experience. Another 13 percent stated "I like to be taken into account by the teacher", "I like to see what others write about" and "it helps listening to what peers say about my work". Therefore, these statements suggest that 
students view formative assessment as more positive than summative practices which some perceive as giving them the feeling of having power. These findings are in line with Liu and Carless' (2006) suggestion that it is better to involve students in giving peer feedback without giving marks.

For the planning stage of this action research project, the themes that were chosen to be peer-assessed were eye contact, gestures and the use of the voice since the students had practiced each of these topics in class and the activity would give then further practice but combining the three topics. The activity designed to introduce peer assessment was a short poem competition. A rubric with several elements of eye contact, gestures and the use of the voice was made. The rubric contained the elements of performance, the names of the contestants and a scale ranging from 1 to 4, being 4 the grade for excellent performance. The criterion for the marks in the scale was discussed by all of the students together and a consensus was reached before the competition began.

In the execution stage, most of the students were excited about the activity but some were nervous and two of these students even refused to participate. Their decision was respected; however they did peer assessed their classmates. After the competition, the students were given the same rubric to place each of the marks given by their classmates and add them to see which elements of performance were their strong points and which ones they had to practice more. Some of the students excelled in their performance and a prize for the highest marks was awarded which consisted of chocolates. They were asked to keep in their portfolio of classroom activities their two rubrics; the ones that they graded and the ones with the marks given by their classmates.

For the reflection and evaluation stage, a written interview was given to the students to take home with questions about their opinions of the activity, the peer assessing experience, being peer assessed and the reasons for these opinions. The students' answers were positive in general. They stated "I really liked the activity", "more activities like this one should be done in other courses", "I found the experience really good because I could see my strong skills", "I liked to see what my classmates thought about my performance", "I was surprised to discover that my classmates graded me similar", "It was [a] successful experience because we discussed the criteria" and "the teacher took us into account". However on the negative side, there were also many comments about students feeling "nervous", which did not really influence their comments of not having liked the experience. In regards to the students that did not participate and as the written interview was anonymous, their answers could not be detected. However at the end of the course, they seemed more integrated because during the course they had to practice and participate in small groups in front of the classmates.

\section{Conclusion}

The action research study was successful in answering both research questions since the students' mixed perceptions about peer assessment surfaced and the negative perceptions were improved. Reflecting on the study, the main points for the success of this experience was first finding a motivating and challenging activity for students to put into practice the theory in course contents. The second point is training students to give and receive peer assessment so that they can perceive a feedback that is credible, honest, knowledgeable and unbiased. A third point is making the students part of the process by discussing or deciding together the criteria to be used. Finally, respecting the students' decisions is an important issue. As the experience was successful, it is important to continue in the training of these students and plan more experiences. In this context, improving negative perceptions is crucial since the participants will be the future teachers of English at all levels of instruction and should be expected to implement peer assessment in their own lessons with their future students. In this field of English language teaching as in other fields of education, it is necessary for teachers to engage in this type of assessment to promote deep learning and to develop critical and responsible human beings who can work in collaboration with others and are able to accept and give feedback.

\section{References}

Binkley, M., Erstad, O., Herman, J., Raizen, S., Ripley, M., Miller-Ricci, M., \& Rumble, M. (2012). Defining Twenty-First Century Skills. In P. Griffin, B. McGaw, \& E. Care (Eds.), Assessment and Teaching of 21st Century Skills. (pp. 17-66). Dordrecht: Springer. http://dx.doi.org/10.1007/97894-007-2324-5_2

Carvalho, A. (2013). Students' perceptions of fairness in peer assessment: evidence from a problem-based learning course. Teaching in Higher Education, 18(5), 491-505. 
De Grez, L., Valcke, M., \& Roozen, I. (2012). How effective are self- and peer assessment of oral presentation skills compared with teachers' assessments? Active Learning in Higher Education, 13(2), 129-142. doi:10.1177/1469787412441284

James, M. \& Pedder, D. (2006). Professional learning as a condition for assessment for learning. In J. Gardner (Ed.), Assessment and learning (pp. 27-44). London: Sage Publications.

Liu, N. F., \& Carless, D. (2006). Peer feedback: The learning element of peer assessment. Teaching in Higher Education, 11(3), 279-290.

Logan, E. (2009). Self and peer assessment in action. Practitioner Research in Higher Education, 3(1), 29-35.

Ndoye, A. (2017). Peer/self-assessment and student learning. International Journal of Teaching and Learning in Higher Education, 29(2), 255-269.

Pellegrino, J. W. (2017). Teaching, learning and assessing $21^{\text {st }}$ century skills. In S. Guerriero (Ed.), Pedagogical knowledge and the changing nature of the teaching profession. Educational Research and Innovation, OECD Publishing, Paris, https://doi.org/10.1787/ 9789264270695-en. Retrieved December 16, 2019 from https://www.oecd-ilibrary.org/education/pedagogical-knowledge-andthe-changing-nature-of-the-teaching-profession_9789264270695-en

Sagor, R. (2000). Guiding school improvement with action research. Alexandria, VA: ASCD.

UNESCO (2013). Making education a priority in the Post-2015 development agenda: report of the Global Thematic Consultation on Education in the Post-2015 Development Agenda. Retrieved on December 16, 2019. https://unesdoc.unesco.org/ark:/48223/pf0000223024 